\title{
Solution of the problem of optimum power distribution of individual compensating devices for a group of asynchronous motors for a stable operating mode and for a smoothly changing load
}

\author{
E.V. Tumaeva, S.S .Kuzin, I.F. Aflyatunov, and T.G. Makuseva \\ Nizhnekamsk Institute of Chemical Technology, Nizhnekamsk, Russia
}

\begin{abstract}
Residential and industrial buildings with large territorial dimensions, have mainly radial power supply schemes, which feed a large number of small and medium capacity $0.4 \mathrm{kV}$ induction motors. For their power supply copper or aluminum cables of small cross-section (with high active resistance) are used. Calculations of electricity losses in such lines show significant values. In order to reduce active power losses in $0.4 \mathrm{kV}$ cable lines, the optimization problem of minimizing active power losses in the radial power supply circuit is solved by optimal distribution of reactive power of a given value between compensating devices. The single-line scheme of power supply of a group of pumps of technological installation of petrochemical production is considered, the mathematical model of the optimization problem on criterion of minimum of active losses in power lines from reactive power flow is made, which limitations are presented as a system of linear algebraic equations. Results of distribution of optimum values of reactive power between compensating devices of asynchronous motors at maintenance of the set $\operatorname{tg} \varphi$ are received. The quantitative estimation of active power loss reduction in power lines at use of capacitor units, which reactive power is optimally distributed, is given.
\end{abstract}

\section{Introduction}

Currently, reactive power compensation devices are installed in transformer substations on the $0.4 \mathrm{kV}$ side, thus unloading power transformers and superior power lines $6 / 10 \mathrm{kV}$. In this case, the $0.4 \mathrm{kV}$ lines supplying electrical installations remain loaded with excess reactive power [1-5]. The rise in electricity tariffs forced power supply specialists to look for ways to reduce electricity bills, so the issues of reducing active power losses have become very urgent [8-11]. The article suggests using the devices of reactive power compensation directly at asynchronous motors, which are the sources of reactive power, thus unloading the supply lines of $0.4 \mathrm{kV}$. The reactive power values of capacitor units are determined as a result of solving the optimization problem according to the criterion of minimum active losses in the lines of $0.4 \mathrm{kV}[6,7]$.

\section{Materials and methods}

The scientific task of minimizing active power losses in $0.4 \mathrm{kV}$ power transmission lines of a radial power supply scheme is posed by solving the optimization problem of the optimal distribution of the reactive power value of compensating devices between a given number of asynchronous motors. The target function of active power losses (1) is a nonlinear function; therefore, the problem posed is nonlinear and is solved using the Lagrange multiplier method.

Losses of active power during transmission of electricity to the consumer are determined by the formula:

$$
\Delta P=\frac{P^{2}+Q^{2}}{U^{2}} R
$$

where $\mathrm{P}$ is the active power flowing along the line, $\mathrm{W}$; $\mathrm{Q}$ is the reactive power flowing along the line, Var; $\mathrm{U}$ is the supply voltage of the line, $\mathrm{V} ; \mathrm{R}$ is the resistance of the power line, Ohm.

When a compensating device is installed at the consumer $\left(Q_{\mathrm{c}} \neq 0\right)$, these losses are reduced to a value

$$
\Delta P=\frac{P^{2}+\left(Q-Q_{c}\right)^{2}}{U^{2}} R
$$

Thus, reactive power compensation allows one to reduce active power losses in power supply circuit and, consequently, to improve the technical and economic performance of this circuit. From expressions (1), (2) it can be seen that power losses $\Delta P$ have two components: the losses from flowing through the active power line $P$ and the losses from flowing through the line of reactive 


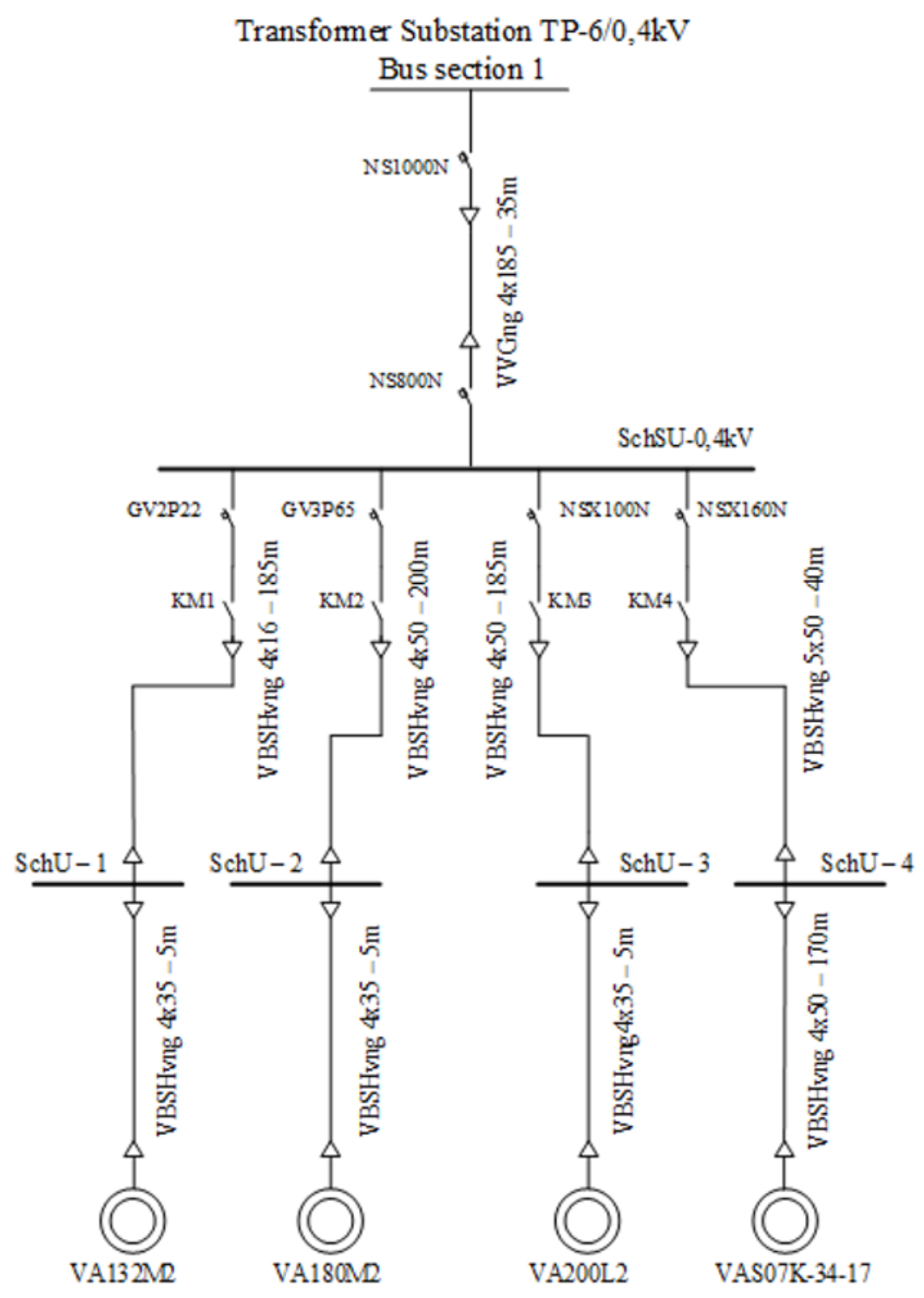

Fig. 1. Single-line scheme of power supply for engines of a group of pumps at a technological installation.

power $Q$, that is $\left(Q-Q_{\mathrm{c}}\right)$. Since the compensation of reactive power affects only the second component of losses, further we will consider the losses of active power only from the flow through the lines of reactive power. For the power supply system, the total power of the compensating devices $Q_{\mathrm{c}}$ may be specified by specific technical conditions. In this case, the specified power $Q_{\mathrm{c}}$ is required to be optimally distributed within the power supply system. This is a conditional optimization problem, which can be solved by the Lagrange method $[12,13]$.

We consider a problem of conditional optimization for the radial scheme of power supply of a group of pumps at a technological unit operating in continuous mode with constant and smoothly changing load is considered. Asynchronous motors $M_{1}, M_{2}, M_{3}, M_{4}$, which consume reactive power $Q_{1}, Q_{2}, Q_{3}, Q_{4}$, are powered by $0.4 \mathrm{kV}$ cable lines from a distribution point with a supply voltage $U=380 \mathrm{~V}$. Active resistances of lines between the source and consumers are $R_{1}, R_{2}, R_{3}$, $R_{4}$. Technical characteristics of motors, cables and circuit breakers are shown in Figure 1. In the pump room there is a technical possibility to install a $Q_{\text {ci }}$ compensating device for each asynchronous motor.

Let's find the optimum distribution between four asynchronous motors of the set total power of compensating devices $Q_{c}$, corresponding to $\operatorname{tg} \varphi=0.35$ on buses SchSU-0,4 kV. We use criterion of optimality minimum losses of active power from jet power flow in the scheme of power supply of group of pumps of technological installation.

The target function to be minimized, which is the active power loss from flowing through the reactive power lines, has the form:

$$
\begin{aligned}
& \Delta P=\left(Q_{1}-Q_{c 1}\right)^{2} \frac{R_{1}}{U^{2}}+\left(Q_{2}-Q_{c 2}\right)^{2} \frac{R_{2}}{U^{2}}+ \\
& +\left(Q_{3}-Q_{c 3}\right)^{2} \frac{R_{3}}{U^{2}}+\left(Q_{4}-Q_{c 4}\right)^{2} \frac{R_{4}}{U^{2}} \rightarrow \mathrm{min}
\end{aligned}
$$


The relative minimum of the target function is found taking into account the following limitation:

$$
Q_{c 1}+Q_{c 2}+Q_{c 3}+Q_{c 4}-Q_{c}=0
$$

The Lagrange function is:

$$
\begin{aligned}
& L=\frac{1}{U^{2}}\left[\left(Q_{1}-Q_{c 1}\right)^{2} R_{1}+\left(Q_{2}-Q_{c 2}\right)^{2} R_{2}+\right. \\
& \left.+\left(Q_{3}-Q_{c 3}\right)^{2} R_{3}+\left(Q_{4}-Q_{c 4}\right)^{2} R_{4}\right]+ \\
& +\lambda\left(Q_{c 1}+Q_{c 2}+Q_{c 3}+Q_{c 4}-Q_{c}\right) \rightarrow \min
\end{aligned}
$$

In order to find the minimum of function $\mathrm{L}$, we calculate its partial derivatives and equate them to zero:

$$
\left\{\begin{array}{l}
\frac{\partial L}{\partial Q_{c 1}}=-\frac{2}{U^{2}} R_{1}\left(Q_{1}-Q_{c 1}\right)+\lambda=0 ; \\
\frac{\partial L}{\partial Q_{c 2}}=-\frac{2}{U^{2}} R_{2}\left(Q_{2}-Q_{c 2}\right)+\lambda=0 ; \\
\frac{\partial L}{\partial Q_{c 3}}=-\frac{2}{U^{2}} R_{3}\left(Q_{3}-Q_{c 3}\right)+\lambda=0 ; \\
\frac{\partial L}{\partial Q_{c 4}}=-\frac{2}{U^{2}} R_{4}\left(Q_{4}-Q_{c 4}\right)+\lambda=0 ; \\
\frac{\partial L}{\partial \lambda}=Q_{1}+Q_{2}+Q_{3}+Q_{4}-Q_{c}=0
\end{array}\right.
$$

We solve the resulting system of linear equations (3), determine the optimal values of reactive powers of the compensating devices $Q_{c 1}, Q_{c 2}, Q_{c 3}, Q_{c 4}$ and find the minimum for active losses $\Delta P$ from flowing along the lines of reactive power.

We would like to note that there are many different methods for solving systems of linear equations. The approach depends on the type of system in question. When solving practical problems, in particular, the one presented above, the hypothesis of a linear representation of the real world can be assumed. Mathematical models of such problems are described, respectively, by linear equations. If the problem is multidimensional, then its mathematical model is represented by a system of linear equations, like the system of equations (3). The solution of systems of linear equations is fully investigated. To solve systems of linear equations, where the number of unknowns is equal to the number of equations, Cramer's formulas and the matrix method are applied. As limitations of their methods, we note the difference from zero of the determinant of the main matrix, since otherwise, the system of equations has no solutions.

In contrast to these methods, the Gauss method can be applied to systems of linear equations with an arbitrary number of equations and unknown ones. It is the most versatile and practically unlimited. With the determinant tending to zero, one can obtain an illconditioned system, for the solution of which a very effective method called regularization has been developed. The number of arithmetic operations in the
Gauss method depends on the dimension of the system; for large $n(n>100)$ the total number of operations is approximately equal to $2 / 3 n^{3}$.

To solve a system of linear equations by Cramer's method, it is necessary to find the $(n+1)$ determinant of the $n$-th order and also make $n$ divisions. When solving by the matrix method, one has to find one determinant of the $n$-th order, $n^{2}$ determinants of the $(n-1)$ order and make $n^{2}$ divisions. As we see, these two methods are characterized by a large number of operations, which sharply increases with the number of $n$.

So, each of the considered methods for solving systems of linear equations provides for the repeated execution of the same operations with a different amount of data. In this regard, it is easy to represent them in the form of algorithms and translate them into a programming language. We would like to note that the disadvantage of the Gauss method in comparison with the Cramer method is that the solution of the system is obtained sequentially, after finding each unknown, when in the Cramer method any unknown is found immediately, it is enough to find only two corresponding determinants.

Nevertheless, the Gauss method is easy to program, compared to the matrix method, which also allows you to find an array of unknowns by matrix multiplication, but it is difficult in terms of creating the right conditions in the programming process. The productivity of using this or that method for solving systems of equations is determined by a combination of various factors, however, in any case, their use is advisable only when the solution to the system exists and it is the only one.

Note that in our study, we solved the system of linear equations (3) in several ways using various mathematical packages. We would like to say that each of the methods used for solving systems of equations has its own advantages and disadvantages. We were interested in the number of operations performed using various methods. The number of unknowns in our system of equations is $n$ $=5$. When using the Gauss method with the choice of the main element, about 115 arithmetic operations were performed at each step. When using Cramer's formulas, you have to calculate 6 determinants of the 5th order and perform 5 division operations, which is more than 600 arithmetic operations. The matrix method is reduced to calculating one determinant of the 5th order, 25 determinants of the 4th order, and carrying out 25 division operations, which corresponds to about 220 operations. Thus, the most optimal is the Gauss method.

Analysis of the results of solving the optimization problem shows that the optimal distribution of a given total value of reactive power on the buses of the distribution point $Q_{\mathrm{c}}$ in the considered radial power supply scheme obeys the equality:

$$
\begin{aligned}
& \left(Q_{1}-Q_{c 1}\right) R_{1}=\left(Q_{2}-Q_{c 2}\right) R_{2}= \\
& =\left(Q_{3}-Q_{c 3}\right) R_{3}=\left(Q_{4}-Q_{c 4}\right) R_{4} .
\end{aligned}
$$

When solving the problem of optimal distribution of a given total reactive power between compensating devices, several factors should be taken into account in 
Table 1. Technical characteristics of asynchronous motors.

\begin{tabular}{|c|c|c|c|c|c|c|c|}
\hline № & Type & $\boldsymbol{I}_{\mathbf{L}}, \mathbf{A}$ & $\boldsymbol{K}_{\mathbf{3}}$ & $\boldsymbol{P}_{\boldsymbol{\Phi}, \mathbf{k W}}$ & $\boldsymbol{t g} \boldsymbol{\varphi} \boldsymbol{\Phi}$ & $\boldsymbol{Q}_{\boldsymbol{\Phi}}, \mathbf{k V a r}$ & $\boldsymbol{Q}_{\mathbf{o p t}}, \mathbf{k V a r}$ \\
\hline 1 & BA180M2 & 52.9 & 1 & 32.58 & 0.51 & 16.70 & 4.7 \\
\hline 2 & BA132M2 & 20.2 & 1 & 12.30 & 0.54 & 6.64 & 0.3 \\
\hline 3 & BA200L2 & 77.3 & 1 & 48.14 & 0.48 & 23.31 & 10.8 \\
\hline 4 & BAC07K-37-14 & 76.3 & 1 & 40.66 & 0.83 & 33.69 & 19.1 \\
\hline
\end{tabular}

Table 2. Technical characteristics of asynchronous motors.

\begin{tabular}{|c|c|c|c|c|c|c|c|}
\hline № & Type & $\boldsymbol{I}_{\mathbf{L}}, \mathbf{A}$ & $\boldsymbol{K}_{\mathbf{3}}$ & $\boldsymbol{P}_{\boldsymbol{\Phi}, \mathbf{k W}}$ & $\boldsymbol{t g} \boldsymbol{\varphi} \boldsymbol{\Phi}$ & $\boldsymbol{Q}_{\boldsymbol{\Phi}}, \mathbf{k V a r}$ & $\boldsymbol{Q}_{\text {opt }}, \mathbf{k V a r}$ \\
\hline 1 & BA180M2 & 52.9 & 0.73 & 23.8 & 0.61 & 14.54 & 7.1 \\
\hline 2 & BA132M2 & 20.2 & 0.8 & 9.74 & 0.62 & 6.00 & 1.7 \\
\hline 3 & BA200L2 & 77.3 & 0.86 & 41.3 & 0.53 & 21.74 & 13.4 \\
\hline 4 & BAC07K-37-14 & 76.3 & 0.7 & 28.16 & 1.01 & 28.45 & 21.2 \\
\hline
\end{tabular}

Table 3. Technical characteristics of asynchronous motors.

\begin{tabular}{|c|c|c|c|c|c|c|c|}
\hline № & Type & $\boldsymbol{I}_{\mathbf{L}}, \mathbf{A}$ & $\boldsymbol{K}_{\mathbf{3}}$ & $\boldsymbol{P}_{\boldsymbol{\Phi}, \mathbf{k W}}$ & $\boldsymbol{t g} \boldsymbol{\varphi} \boldsymbol{\Phi}$ & $\boldsymbol{Q}_{\boldsymbol{\Phi}}, \mathbf{k V a r}$ & $\boldsymbol{Q}_{\mathbf{o p t}}, \mathbf{k V a r}$ \\
\hline 1 & BA180M2 & 52.9 & 0.73 & 23.80 & 0.61 & 14.54 & 9.5 \\
\hline 2 & BA132M2 & 20.2 & 0.8 & 9.74 & 0.62 & 6.00 & 2.9 \\
\hline 3 & BA200L2 & 77.3 & 0.3 & 14.93 & 1.19 & 17.84 & 15.3 \\
\hline 4 & BAC07K-37-14 & 76.3 & 0.7 & 28.16 & 1.01 & 28.45 & 23.6 \\
\hline
\end{tabular}

Table 4. Technic al characteristics of asynchronous motors.

\begin{tabular}{|c|c|c|c|c|c|c|c|}
\hline № & Type & $\boldsymbol{I}_{\mathbf{L}}, \mathbf{A}$ & $\boldsymbol{K}_{\mathbf{3}}$ & $\boldsymbol{P}_{\boldsymbol{\Phi}}, \mathbf{k W}$ & $\boldsymbol{t g} \boldsymbol{\varphi} \boldsymbol{\Phi}$ & $\boldsymbol{Q}_{\boldsymbol{\Phi}}, \mathbf{k V a r}$ & $\boldsymbol{Q}_{\text {opt }}, \mathbf{k V a r}$ \\
\hline 1 & BA180M2 & 52.9 & 0.73 & 23.80 & 0.61 & 14.54 & 7.6 \\
\hline 2 & BA132M2 & 20.2 & 0.35 & 4.34 & 1.18 & 5.10 & 1.9 \\
\hline 3 & BA200L2 & 77.3 & 0.86 & 41.31 & 0.53 & 21.74 & 13.9 \\
\hline 4 & BAC07K-37-14 & 76.3 & 0.7 & 28.16 & 1.01 & 28.45 & 21.6 \\
\hline
\end{tabular}

the mathematical model. As a rule, in petrochemical and oil refineries, asynchronous motors operate in a continuous mode with a partial load, therefore it is necessary to determine the active and reactive power of the asynchronous motor taking into account the load factor. If the electrical installation is equipped with meters of active and reactive energy, you can obtain the required power values from the measurement results. In case the electric installation is equipped with active and reactive energy meters, it is possible to obtain the required power values from the measurement results. If there are no electricity metering devices on the object, the actual values of active and reactive power of asynchronous motors with the load factor taken into account can be determined by the method given in [14]. When determining the active resistances $R_{\mathrm{i}}$, all components of the three-phase power transmission line should be taken into account in the section from the motor to the buses of the SchSU- $0,4 \mathrm{kV}$, that is, the active resistance of the cable should be determined taking into account the number of phases and the ambient temperature, and the transition resistance of the contact connections should also be taken into account and the resistance of detachable contacts of magnetic starters and circuit breakers.

From table 1-4 it can be seen that when the load factor $K_{\mathrm{z}}$ changes, the parameters of the motor and the value of the optimal power of the compensating device for each asynchronous motor do change.

\section{Results}

For the above four cases of loading asynchronous motors, losses in $0.4 \mathrm{kV}$ lines were calculated for the power supply scheme shown in Figure 1, from the flow of reactive currents for the case of optimal distribution of compensating devices directly from induction motors $\Delta \mathrm{P}_{\mathrm{Q} o p t}$, from the flow of reactive currents without compensation devices reactive power $\Delta \mathrm{P}_{\mathrm{Q}}$, as well as total active losses in $0.4 \mathrm{kV}$ lines without reactive power compensation $\Delta \mathrm{P}_{\Sigma}$. The calculation results are shown in Table 5.

It is obvious that the application of the results of solving the problem of optimal distribution of reactive power of compensating devices according to the criterion of minimum losses in lines will significantly reduce losses from the flow of reactive currents and total losses in general.

In order to create an automated electrical complex for a group of asynchronous electric motors with an optimal power distribution of compensating devices and integration into the complex of the calculation algorithm of the optimization problem discussed above, the software product "SaveEnergy" was developed based on Visual Studio with $\mathrm{C} / \mathrm{C}++$ support, which allows the user (control system) to quickly select the power compensating devices to a group of asynchronous electric motors connected radially to one load node. The capacities of the capacitor units are calculated by the 
program according to the criterion of the minimum energy losses in the distributed cable lines of the factory power supply [15-17]

\section{Conclusions}

The practical significance of the research results lies in minimizing active power losses from the flow of reactive power and, as a consequence, minimizing active losses in $0.4 \mathrm{kV}$ lines, power transformers and upstream power lines in general. Currently, the authors are developing an automated electrical complex for a group of asynchronous electric motors with an optimal power distribution of compensating devices. In order to increase the speed of the control system when the load of asynchronous motors changes, the calculation algorithm uses the Gauss method to determine the optimal power values of the compensating devices.

\section{References}

[1] A. Feshin, V.S. Chudny, A.N. Belyaev, Transient stability of oil-field isolated power systems with magnetically controlled shunt reactors, 2016 Proceedings of the 2016 IEEE North West Russia Section Young Researchers in Electrical and Electronic Engineering Conference, EIConRusNW, 7448244, 557-561 (2016)

[2] N. Belyaev, A. Egorov, N. Korovkin, V. Chudny, Economic aspects of ensuring the capacity adequacy of electric power systems, E3S Web of Conferences 58, 01010 (2018)

[3] A.V. Gudkov, D.N. Dadonov, E.A. Krotkov, O. Krasulina, N. Akobiya, Research features of voltage static load characteristics in the electric system of Russia, 2018, 2017 6th International Conference on Reliability, Infocom Technologies and Optimization: Trends and Future Directions, ICRITO 2017, 295-300 (January 2018)

[4] A.N. Belyaev, K.A. Izotova, I.V. Kashin, Stability of ultra long distance AC power transmission lines with controlled shunt compensation devices, Proceedings of the 2018 IEEE Conference of Russian Young Researchers in Electrical and Electronic Engineering, ElConRus 2018, 572-576 (January 2018)

[5] N.A. Sobgaida, L.N. Olshanskaya, A.B. Solodkova, Ecological problems of utilization of waste activated sludge of saratov refinery and ways to solve them, Chemical and Petroleum Engineering 47, 3, 198-203 (2011)

[6] V.V. Karagodin, D.V. Rybakov, Optimization of placement of reactive power compensation devices in distribution electric networks, Voprosy ehlektromekhaniki, 1, 43-50 (2014)

[7] V. Vanin, A. Bulychov, M. Popov, O. Vasilyeva, M. Shakhova, About influence of non-sinusoidal currents and voltages on the amount of the electric energy, MATEC Web of Conferences 245, 06009 (2018)

[8] N.V. Korovkin, Q.S. Vu, R.A. Yazenin, A method for minimization of unbalanced mode in threephase power systems, Proceedings of the 2016 IEEE North West Russia Section Young Researchers in Electrical and Electronic Engineering Conference, EIConRusNW 2016, 7448257, 611-614 (2016)

[9] P.V. Chernyaev, M.A. Khazov, A.N. Belyaev, Operating condition analysis of flexible AC transmission lines with controlled series and shunt compensation devices, Proceedings of the 2018 IEEE Conference of Russian Young Researchers in Electrical and Electronic Engineering, ElConRus 2018, 598-603 (January 2018)

[10] I.G. Akhmetova, N.D. Chichirova, Existing approaches to energetic survey of fuel and energy complex organizations, Journal of Engineering and Applied Sciences 11, 13, 2930-2933 (2016)

[11] V.M. Borovkov, L.V. Zysin, V.V. Sergeev, The totals and technological problems of usage of vegetative biomass and organic waste in power engineering, Izvestiya Akademii Nauk, Energetika 6, 13-24 (2002)

[12] V.N. Kostin, Optimization problems of electric power industry (Saint Petersburg, Publishing house of the North-West Technical University, 2006) 128

[13] E.V. Tumaeva, A.V. Popov, Algorithm for calculation the optimal currents of a torque valve motor in the steady state operation, Vestnik Kazanskogo Tehnologicheskogo Universiteta 46, 19, 86-91 (2011)

[14] R.V. Belyavsky, Analysis of the influence of the load factor of asynchronous engines on the consumption of reactive power, Vestnik Kazanskogo Tehnologicheskogo Universiteta, 6, 66-69 (2010)

[15] E.V. Tumaeva, S.S. Kuzin, Minimization of active power losses in cable transmission lines of $0.4 \mathrm{kV}$ at petrochemical and oil refining enterprises, Vestnik Chuvashskogo Universiteta, 1, 154-160 (2019)

[16] O.V. Shemelova, E.V. Yakovleva, T.G. Makuseva, I.I. Eremina, O.N. Makusev, Solving optimization problems when designing power supply circuits, E3S Web Conf: International Scientific and Technical Conference Smart Energy Systems 2019 (SES-2019) 124, 201912404011 (2019)

[17] E.V. Tumaeva, S.S. Kuzin, E.N. Gavrilov, Minimazation of active capacity losses in cable power lines of $0.4 \mathrm{kV}$ using optimally distributed compensating devices at petrochemical and oil refining enterprises, IOP Conference Series: Materials Science and Engeneering 643, 1, 012100 (2019) 